\title{
Customização de Sistemas ERP: Especificação de um processo baseado na Norma ISO 12207
}

Jefferson Blaitt ${ }^{1}$, Mauro de Mesquita Spinola ${ }^{2}$, Ivanir Costa ${ }^{2}$

${ }^{\mathrm{l}}$ ICET - Universidade Paulista (UNIP) - Campus Sorocaba

Av. Independência, 412 - Edén - CEP 18087-101 - Sorocaba - SP - Brasil

2Programa de Pós-graduação - Universidade Paulista - (UNIP)- Campus Indianópolis Rua Dr. Bacelar, 1212 - Vila Clementino - CEP 04026-002 - São Paulo - SP - Brasil

$$
\text { blaitteacm.org, mauro.spinolaepoli.usp.br }
$$

Abstract. The customization process of the integrated system management, denominatedERP systems, is realized in the organization during the system implementation phase and it's considered as a traumatic phase almost all the time, when you can observe the same problems frequently founded in the software development. Based in a customization process analysis in comparison with the software maintenance process, the experiences and researches made before in the second topic were used to improve the first one. In these researches, taking as bases the ABNT ISO/IEC12207 rules, which treats the software life cycle process, a formal process of ERP systems customization will be proposed.

Resumo. O processo de customização de sistemas de gestão integrada. denominados sistemas ERP, é realizado durante a fase de implantação do sistema na organização e muitas vezes é considerado como uma fase traumática, onde são observados os mesmos problemas que freqüentemente são encontrados no processo de desenvolvimento de software. Através de uma análise do processo de customização em comparação ao processo de manutenção de software, procurou-se aproveitar as experiencias e estudos ja documentados neste último para aperfeiçoar o primeiro. Neste estudo, tomando-se como base a Norma ABNT ISO/IEC 12207 que trata do processo de ciclo de vida de software, será proposto um processo formal de customização de sistemas ERP.

\section{Introdução}

Desde o início dos anos 90 a idéia de adquirir um software de gestão empresarial como alternativa ao desenvolvimento de sistemas nas próprias empresas têm sido a tônica de inúmeros estudos acadêmicos e discussões, no mercado, entre os defensores de uma ou da outra iniciativa.

A partir daí, a iniciativa de substituir os sistemas de informações existentes, muitas vezes elaborados por equipes internas de desenvolvimento, pelos chamados pacotes de Reftware ganhou força. Desde então, a adoção de sistemas denominados Enterprise organce Planning (ERP) proporcionaram vantagens significativas para as organizações, desde a padronização de procedimentos através das melhores práticas do 
mercado até a implantação de mecanismos de apoio à decisão como: simulado estatísticos, mineração de dados e gestão do conhecimento (Lozinsky, 1996).

A principal dificuldade na adoção de um produto acabado, ou pacote, de software esta na escolha do sistema mais adequado às necessidades da empresa e muitas vezes, focalizarem a informação, as empresas passam a abordar a forma pela qual serão capazes de obter desempenho superior, transformando a estratégia em alguma coisa concreta e operativa (McGee \& Prusak, 1994). Porém, na maioria das vezes é necessário fazer adequações no sistema adquirido para atender necessidades específicas da organização adquirente do ERP. Estas adequações são denominadas customizações.

Neste artigo vamos abordar o processo de customização de sistemas ERP sob o ponto de vista da Qualidade de Software.

\section{Customização de sistemas vista como uma atividade de manutenção de} software

\subsection{O Processo de Customização do Software ERP}

Lozinsky definiu o processo de customização como qualquer modificação no sistema de informação necessária para adequá-lo às especificidades das regras de negócio da corporação onde o sistema será implementado (Lozinsky, 1996).

Customizar um sistema ERP não é uma tarefa simples, a grande maioria deles foram concebidos para empresas globais, ou seja, que utilizam regras de negócios aplicadas mundialmente, e ainda mais, esses sistemas podem ser implantados em empresas dos mais variados ramos de atividade, não só na manufatura onde sua presença é mais indicada, mas também em empresas de comércio e serviços.

Esta diversidade de ambientes faz com que o sistema ERP assuma uma grande complexidade, porém ele deve ser maleável o suficiente para que possa ser adequado aos diversos ambientes da forma mais simples possível

Os fornecedores de sistemas ERP oferecem várias alternativas de adequação do sistema às necessidades das empresas adquirentes, desde a simples parametrização como o uso de templates para as mais diversas áreas de negócios, modularização, migração e conversão de dados de sistemas legados, até a adequação das tabelas nos bancos de dados (Blaitt, 2000)

Porém, a customização mais crítica está na geração de código em função do atendimento de requisitos de negócio que não são atendidos pelo ERP original e é através deste procedimento que o ERP vai adquirindo as especificidades da empresa onde está sendo implantado, entretanto as conseqüências podem ser desastrosas.

O desenvolvimento de novas funcionalidades que serão agregadas ao ERP original para atender requisitos específicos da empresa deve ser evitado ao máximo, porém em várias situações o ERP deixa de atender requisitos considerados estratégicos para o negócio e o desenvolvimento de novas funcionalidades passa a ser inevitável.

Pode-se comparar a customização de pacotes de software com a tarefa de desenvolvimento de um sistema de informação onde é necessário o levantamento das funcionalidades requeridas, análise, projeto e implementação das alterações que serão realizadas (Pressman, 2002) fa de customizacão de pacotes de software

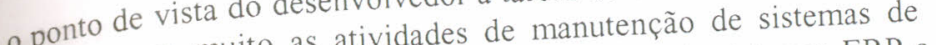
se asivel então fazer um paranformação.

manutenção de sisterr

2.2. O Processo de Manutenção de Software E manutenção esteja presente em todas as definções de ciclo mesma profundidade software, na maioria das vezes o assunto não é aborda

destinada as atividades de desenvolvimento de softwara modificação de um 0 processo de manutenção de software pode ser conce para corrigir falhas, melhorar o produto de software, depois de liberado para usonte alterado (ANSI/IEEE, 1983). desempenho ou para adaptar o produto a um ambesta da abordagem desta definição. O termo E necessão na sua essência, é aplicado para manter um componente emfare devemos manuteçonamento. Porém, quando tratamos de manutençám ser analisados.

considerar um ambiente mais complexo e vários aspectos devem "perfeito estado de funcionamento" pode Primeiro, o software que deve ser mantido em "perfeito estado de fucionazo deve ser nem sequer estar funcionando corretamente. Neste caso a te software.

considerada como manutenção, mas de depuração ou teste de software. Em uma segunda abordagem, existem as melhorias que devem ser acrescentadas a ser software, ou ainda, melhorias nas caracteristicas antigas. Esta pode exigir grande considerada como evolução contínua

esforco de análise e desenvolvimento. Por último, existe a necessidade de manutenção devido a influências do moverno, hardware e como mudanças no sistema operaci

alterações em processos produtivos. Em 1976, Swanson propôs uma classificação para a manu
áreas que é utilizada até os dias de hoje (Swanson, 1976).

\subsubsection{Manutenção corretiva}

resentam falhas ou não atendem os eressman, 2002), é razoável especificacoes originais. Segundo Roger Pressman (Prebirá todos os erros latentes presumir que a atividade de teste de software dificilmente cobrira todos õ erelatados erros num grande sistema de software e durante a utiliza

que deverão ser corrigidos pelo desenvolvedor.

\subsubsection{Manutenção adaptativa} mo quando é encontrada uma mudança em qualquer aspecto que envolva o ambião à computacional onde o software está instalado ou quando há necessidadimento as novas nova legistaça, ou ainda mudanças no processo produtivo em atendim necessidades do negócio. 


\subsubsection{Manutenção evolutiva}

E o processo que visa o aperfeiçoamento do software e que inclui melh performance, inclusões de novas características e modifica ques necessárias horias mudança dos requisitos inicialmente estabelecidos. modificaçoes necessárias devid a

\subsection{A customização como um processo de manutenção}

O processo de customização de sistemas ERP não pode

processo de Manutenção Corretiva visto que não pode ser classificado como apresenta falhas em seu funcionamento. Tambéma que está sendo adaptado como um processo de Manutencão é feito pelo fornecedor e as novas melhorias jão que o aperfeiçoamento do sistema ER lançadas novas versões do sistema. Podemos então anexadas ao ERP original quando sã processo de Manutenção Adaptativa já que então classificar a customização como adequações de atendimento a requisitos de negóciotıvos das modificações referem-se

\section{Customizando com Qualidade}

Conforme foi apresentado, o processo de customizacão de sistemas classificado como sendo um processo de Manutençação de sistemas ERP pode ser integrante do ciclo de vida do desenvolvimentonção Adaptativa e desta forma é parte realizada observando-se os princípios da quanto de software. A customização deve se um processo claro e bem estabelecido do processo de software, ou seja, deve-se defini processo de customização.

Informação - Processos de Ciclo de Vide (ISO 12207) denominada Tecnologia de ser utilizada por desenvolvedores dovê uma estrutura comum par (ama padronizaço nos de software desção e gerência de software. A estrutura proposta cobre o ciclo de vida de software desde a concepção de idéias até a descontinuação do software (Rocha

Segundo a descrição constante na norma, a ISO 12207 agrupa as atividades que deven ser executadas durante o ciclo de vida de processos de apoio e processos organizacion software em processos fundamentais, e

de vidassos fundamentais constituem um conjunto de cinco processos durante o ciclo Processo de Software, são eles: Processo de Aquisição; Processo de Fornecimento Processo de Desenvolvimento; Processo de Operação e Processo de Manuteñãnento Um processo de apoio aucilia propósito distinto, e contribui um outro processo como uma parte integrante, com um processo de apoio é empregado ex do software. Um processos de processo. Os Qualidade; Verificação; Validaç̃o: Reção; Gerência de Configuração; Garantia da de Resolução de Problemas.

Os processos organizacionais são empregados por implementar uma estrutura são empregados por uma organização para estabelecer e pessoal associados, e melhorar continuamente a estáda de processos de ciclo de vida e nosso estudo abordaremos exclusivamente o processo de manutenção (figura 1 ) para nosso dos Processos Fundamentais do ciclo de vida de software e está definido que faz parte dos

na Norma como:

nrocesso de Manutenção contém as atividades e tarefas do mantenedor. Este "O Processo de quando o produto de software é submetido a modificações no código processo e ativa e na documentação associad devido a um problema, ou à necessidade de melhoria ou e na dã̃o. O objetivo é modificar um produto de software existente, preservando a sua adaptação. O (ISO 12207)



Resolução de Problemas

\begin{tabular}{|l|}
\hline \multicolumn{1}{l}{ Processos Organizaci } \\
\hline Gerência \\
\hline Melhoria \\
\hline
\end{tabular}

igura 1 - Ciclo de vida de software adaptada da Norma 12207, com o processo de manutenção em destaque.

A Nor

manutena apresenta um conjunto de atividades que caracterizam o processo de do Processo e cria a figura do Mantenedor. O Mantenedor é responsável pela gerência
Infra Estrutura

Treinamento 
necessária para o processo, fazer as adaptações necessárias no processo em funcão projeto, gerenciar o processo em nível organizacional e deve agir em conformidade con os demais processos descritos.

As atividades previstas para o Processo de Manutenção são: 1) Implementaçào processo; 2) Análise do problema e da modificação; 3) Implementação da modificação 4) Revisão/aceitação da manutenção; 5) Migração e 6) Descontinuação do softwara; Cada uma destas atividades estão especificadas na Norma através de tarefas específicas.

\subsection{A ISO 12207 aplicada a customização de sistemas ERP}

A Norma ISO 12207 foi utilizada como base para definir um Processo de Customizacão de Sistemas ERP

\subsubsection{Definição do Customizador}

O processo de customização deverá ser gerenciado por um Customizador que deverá ser nomeado pela equipe de projeto de implantação do sistema ERP e deve atuar como interface entre esta equipe e a equipe de customização. O Customizador deverá ser responsável pela execução das atividades de customização.

\subsubsection{As Atividades de Customização}

Apoiados nas atividades do Processo de Manutenção descritas na Norma ISO 12207 é proposto um Processo de Customização que deverá ser utilizado como base para as ações do Customizador, que deverá agir em conformidade com as tarefas estabelecidas.

O Processo de Customização proposto consiste das seguintes atividades:

\section{a) Implementação do processo de customização}

O Customizador deve desenvolver, documentar e executar planos e procedimentos para a condução das atividades e tarefas do Processo de Customização. Deve também estabelecer procedimentos para receber, registrar e rastrear relatórios de problemas e pedidos de customização solicitados pela equipe de implementação. Este processo deve ser formalizado e pode ser definido como um processo de gerência de configuração de customizações.

\section{b) Análise da customização}

Diferentemente da função do mantenedor descrita na Norma ISO 12207 que avalia a necessidade de manutenção do software e seu impacto sobre a organização e nos diversos sistemas com os quais o sistema em manutenção interage, o Customizador deve focar seus esforços na análise da customização propriamente dita. A tarefa de avaliar quais Customizações deverão ser realizadas e quais os impactos destas alterações no sistema em implantação é função da equipe de implantação.

O Customizador deve então desenvolver alternativas para a implementação da customização, documentar o pedido de customização, o resultado da análise, as alternativas de implementação e obter aprovação da alternativa selecionada junto ? equipe de implantação. c) Implementação da customização -anformidade com o Customizador deve utilizar um processo de desenvolvima O Custecido para o desenvolvimento de soltementados, como segue:

processo de desenvolvimento devem ser complementados, como segre: definidos e documentados critérios de teste e de avaliação para to Devem ser definidos e domizados e os impactos da customização sobre o sistema avaliar os módulos customponentes e itens de configuração).

(unidades de software co requisitos novos. Também Deve ser garantida a implementação completa e condificados não foram afetados. Os deve ser garantido que os requisitos originais na

resultados dos testes devem ser documentac

d) Revisão/aceitação da customização Customizador deve conduzir a revisão em conjunto coma equpe de implenentaça do sistema para determinar a integridade da customização realizada e deve obter do sistema para a conclusão satisfatória da customização, conforme solicitação da aprovação para a conclusã

ASO 12207 prevê ainda no processo de manutenção as atividades de A Norãa e Descontinuação do Software. Podemos entender que do ponto de vista da customização de sistemas ERP nenhuma das duas atividades se enquadramão no características de Manutenção Adaptativa. A primeira por se tratar de alteração no ambiente de operação do sistema e a segunda por abordar a desativação do sistema em operãão. Portanto, neste estudo não será proposta nenhuma equivalência entru operaça matencão da Norma ISO 12207 e o Processo de Customização aqui abordado.

\section{Conclusão}

A customização de sistemas ERP não pode ser tratada como uma tarefa independente do ciclo de vida de uma adequação mal implementada podem significar o fracasso do processo de implantação do pacote.

Embora esta afirmação seja compartilhada pelos analistas/consultores de implantação, não é comum encontrar estudos sobre o processo de customização. As referências a este tema são encontradas em textos sobre implantação de sistemas ERP e muitas vezes é tratado com superficialidade.

Esta mesma observação pode ser comprovada com relação à manutenção de software, que embora comprometa a maior parte do ciclo de vida de software não é destaque na literatura especializada.

A relação entre a customização de um sistema ERP e a manutenção de software pode trazer uma nova luz sobre o processo de customização, visto que podemos aproveitar muitas das experiências estudos realizados sobre manutenção e aplicar diretamente, total ou parcialmente, nos projetos de implantação de sistemas ERP, particularmente no processo de customizacão de sistemas ERP. 
Definir um processo de customização baseado em uma Norma utilizada nas discipli de Engenharia e Qualidade de Software pode trazer grandes benefícios para as equip de implantação de sistemas integrados, principalmente por padronizar procediment que atualmente são executados sem critérios de qualidade definidos.

A efetiva documentação das customizações realizadas através de um processo gerência de configuração das customizações permitirá uma rastreabilidade d adaptações e esta premissa é fundamental no momento da troca de versão do sisten ERP garantindo que o trabalho realizado na customização da versão anterior possa efetivamente aproveitado na nova versão.

Este estudo apresentou uma pequena introdução sobre o assunto e propos estabelecimento de um processo formal de customização de sistemas ERP baseado na Norma ABNT ISO/IEC 12207/1997 que aborda o ciclo de vida de processo de software e apresenta um procedimento específico para a manutenção de software, o qual fo adaptado para o processo de customização.

Em estudos futuros deve-se desenvolver um estudo empírico para verificar aplicabilidade do modelo proposto.

Acreditamos que o tema em estudo deve ser aprofundado e possivelmente caminhar para o estabelecimento de metodologias de implantação de sistemas ERP baseados em conceitos de engenharia e qualidade de software.

\section{Referencias}

ANSI/IEEE (1983) "An American National Standard IEEE Standard Glossary of Software Engenering Terminoly", IEEE Transaction on Software Engeneering.

Blaitt, Jefferson e Spinola, Mauro (2000) "Customização de sistemas globais de gestão empresarial:uma visão de qualidade de software". Anais do XX Encontro Nacional de Engenharia da Produção - ENEGEP, São Paulo.

ISO/IEC 12207 (1997) "Projeto de norma, ABNT Associação Brasileira de Normas e Técnicas", ABNT,

Lozinsky, Sérgio. (1996) "Tecnologia do Negócio: em busca de benefícios e de sucesso na implementação de pacotes de software integrados". Imago Editora, Rio de Janeiro.

McGee, James V., Prusak, L. Gerenciamento Estratégico da Informação, Rio de Janeiro, Campus, 1994.

Pressman, Roger S. (2002) "Engenharia de Software", 5a Edição, McGraw-Hill, São Paulo.

Rocha, Ana Regina Cavalcanti, et alli.(2001) "Qualidade de Software: Teoria e Prática" Prentice Hall, Rio de Janeiro.

Swanson, E. B.(1976) "The Dimensions of Maintenance", Proc. IEEE/ACM 2nd. Int. Conf. on Software Eng. 